\title{
A case study of correspondence between Pc1 activity and ionospheric irregularities at polar latitudes
}

\author{
P. Francia ${ }^{1 *} \mathbb{D}$, M. Regi ${ }^{2}$, M. De Lauretis ${ }^{1}$, M. Pezzopane ${ }^{2}$, C. Cesaroni ${ }^{2}$, L. Spoglili, ${ }^{2,3}$ and T. Raita ${ }^{4}$
}

\begin{abstract}
A possible driver of precipitation of magnetospheric energetic electrons in the high-latitude atmosphere is represented by electromagnetic ion-cyclotron (EMIC) magnetospheric waves. The precipitating particles produce variations, by collision, in the ionized component of the atmosphere, altering its chemistry and electrical conductivity, with a significant impact on the atmospheric processes. In this framework, it would be significant to find experimental evidence of a correspondence between ionospheric electron density irregularities and the occurrence of Ultra-LowFrequency (ULF) PC1 geomagnetic pulsations, i.e., the ground signatures of EMIC waves, at high latitudes. In this work, we face this subject by considering a specific case study occurred on 22 February 2007 during quiet magnetospheric conditions. The study is based on the analysis of simultaneous ULF geomagnetic field and Total Electron Content (TEC) measurements recorded at Mario Zucchelli Station in Antarctica. We show that Pc1 pulsations occur in correspondence to solar wind pressure increases and that, at the same time, the ionosphere is characterized by the presence of ionospheric irregularities. We suggest that a possible link between the Pc1 activity and the ionospheric irregularities may be energetic electron precipitations, driven by EMIC waves generated in the compressed magnetosphere, which produce density variations in the ionized component of the atmosphere.
\end{abstract}

Keywords: ULF waves, lonospheric irregularities, Solar wind

\section{Introduction}

Ultra-Low-Frequency (ULF) Pc1 waves $(f \sim 0.2-5.0 \mathrm{~Hz})$ are known to be generated by the electromagnetic ioncyclotron (EMIC) resonance in the equatorial magnetospheric regions with unstable, energetic ions, such as ring current and plasma sheet ions during disturbed geomagnetic conditions (Menk 2011). In addition, during geomagnetically quiet periods even modest compressions of the magnetosphere, due to solar wind dynamic pressure increases, can be responsible for magnetospheric plasma instabilities just inside the dayside magnetopause, driving Pc1 waves (Anderson and Hamilton 1993; Engebretson et al. 2002; Usanova et al. 2008, 2012). A statistical study

\footnotetext{
*Correspondence: patrizia.francia@aquila.infn.it

${ }^{1}$ Dipartimento di Scienze Fisiche e Chimiche, Università degli Studi dell'Aquila, L'Aquila, Italy

Full list of author information is available at the end of the article
}

by Park et al. (2016) shows that, during quiet conditions, geosynchronous EMIC waves are mostly triggered by solar wind pressure enhancements, and they occur from morning to afternoon with an occurrence peak around noon.

Such waves are transmitted as Alfven waves along geomagnetic field lines into the auroral ionosphere and then, after being converted into compressional waves, they propagate horizontally in the waveguide represented by the ionosphere, becoming linearly polarized well far from the injection region (Greifinger and Greifinger 1968; Greifinger 1972; Fraser 1975; Fujita and Tamao 1988). Since ionospheric waveguide boundaries are not perfect reflectors, the waves are attenuated when propagating (Manchester 1966); moreover, several studies (Hayashi et al. 1981; Kim et al. 2010, 2011; Regi et al. 2017a) showed that their poleward propagation is more efficient and that these waves can be detected also at polar 
latitudes. A statistical study based on experimental measurements from an Antarctic magnetometer array over a very large range of geomagnetic latitudes $\left(-62^{\circ}\right.$ to $-87^{\circ}$, spanning $2920 \mathrm{~km}$ geographically) showed that they propagate from the injection region with power attenuation factors of 10-14 dB/1000 km (Kim et al. 2011). Moreover, the results of a numerical modeling presented by Fedorov et al. (2018) indicate that, at distances smaller than $600 \mathrm{~km}$ from the injection point, the wave amplitude decreases by $\sim 1 \mathrm{~dB} / 100 \mathrm{~km}$ during nighttime and by $\sim 10 \mathrm{~dB} / 100 \mathrm{~km}$ during daytime, while at distances larger than $600 \mathrm{~km}$ the nighttime and daytime attenuation rates are approximately the same, $\sim 1 \mathrm{~dB} / 100 \mathrm{~km}$.

Observational evidences show that Pc1 waves are responsible for the relativistic electron precipitation into the high-latitude $\left(60^{\circ}-70^{\circ}\right)$ ionosphere (Rodger et al. 2008; Clilverd et al. 2010; Blum et al. 2015). Indeed, Pc1 waves can resonate with $>1 \mathrm{MeV}$ outer radiation belt electrons and scatter them into the loss cone (Engebretson et al. 2008 and references therein). Recent works (Ukhorskiy et al. 2010; Hendry et al. 2017) show evidence of sub-MeV electron precipitations driven by EMIC waves, with electron energies of several hundred $\mathrm{keV}$. Through ionization processes, precipitating electrons can modify both the chemistry and the electric conductivity of the atmosphere, with potential effects on local or even global climate (Mironova et al. 2015). Recent statistical studies have shown significant effects of Pc1 activity on atmospheric properties at stratospheric and tropospheric altitudes in Antarctica (Francia et al. 2015; Regi et al. 2016, 2017b).

Thus, the electron precipitation, modulated by the variability of the geomagnetic activity, produces ionospheric electron/ion density variations (often steep gradients), commonly referred as "ionospheric irregularities".

The high-latitude ionospheric irregular structures are usually hosted in the boundaries of the auroral oval and within the polar cap and, being driven and modulated by the geospace forcing, intensify under disturbed geomagnetic conditions (see, e.g., Spogli et al. 2009; Alfonsi et al. 2011).

The presence of ionospheric irregularities can be revealed by measurements of Total Electron Content (TEC) and in particular by its Rate Of Change (ROT), both derived by Global Navigation Satellite System (GNSS) receivers (see, e.g., Basu et al. 1999).

In this work we investigated the correspondence between long-lasting narrowband Pc1 activity and the occurrence of ionospheric irregularities at high latitude using a case study. To carry out the analysis, ULF geomagnetic field and TEC measurements recorded at the Italian Mario Zucchelli Station (MZS, Terra Nova Bay, Antarctica) were considered.

\section{Data and analysis methods}

We analyzed Pc1 pulsations measured at MZS (geographic coordinates $74.69^{\circ} \mathrm{S}, 164.12^{\circ} \mathrm{E}$, corrected geomagnetic coordinates $80.03^{\circ} \mathrm{S}, 307.74^{\circ} \mathrm{E}$; local time $(\mathrm{LT})=$ universal time $(\mathrm{UT})+11$, magnetic local time $(\mathrm{MLT})=\mathrm{UT}-8)$ during 22 February 2007. We focused our attention on the time interval 02-14 UT (18-06 MLT at MZS, i.e., between the local magnetic evening and the local magnetic morning), excluding hours close to the magnetic noon when the region of interest approaches the polar cusp and measurements are characterized by large broadband fluctuations. The examined time interval was geomagnetically quiet (with the geomagnetic index AE ranging between 10 and $80 \mathrm{nT}$ ), so that, in absence of large storm/substorm disturbances, Pc1 wave packets were clearly detectable. Measurements were performed by a search-coil magnetometer, which provides variations of the geomagnetic field in the northward $\mathrm{H}$, eastward $\mathrm{D}$, and vertically downward $\mathrm{Z}$ components at a $4 \mathrm{~Hz}$ sampling rate. To reduce aliasing, a low-pass filter was applied so that the response at frequencies greater than $1500 \mathrm{mHz}$ was strongly dampened.

Applying the Welch's method (Welch 1967), we computed the power spectral density (PSD) over 300-s time intervals, using the Hamming window (Elliot 1987) and averaging 100 -s sub-intervals overlapping by $50 \%$, with a correspondent frequency resolution of $10 \mathrm{mHz}$. Spectra were converted using the instrument transfer function from $\mathrm{mV}^{2} / \mathrm{Hz}$ to $\mathrm{nT}^{2} / \mathrm{Hz}$. Dynamical spectra were obtained using 300-s non-overlapping spectra.

Moreover, to better identify the pulsation signals, we computed the signal-to-noise ratio $\operatorname{SNR}(f)$ (De Lauretis et al. 2010; Ponomarenko et al. 2002) for each 300-s interval, as follows:

$$
S N R(f)=\frac{S(f)}{N(f)}=\left[\frac{S_{T}(f)-N(f)}{N(f)}\right]=\frac{S_{T}(f)}{N(f)}-1,
$$

where $S_{T}(f)$ is the experimental total (signal+noise) power spectrum, $S(f)$ the power spectrum of the unknown signal, and $N(f)$ the background noise; $N(f)$ was estimated by fitting a linear function to the $\log \left(S_{T}\right)-\log (f)$ dependence at the extremes of the $100 \mathrm{mHz}-1 \mathrm{~Hz}$ frequency range:

$$
\log (N)=\propto \log (f)+\beta .
$$

Our method does not reveal impulsive, broadband signals whose power spectra do not emerge significantly from the corresponding noise spectra (Regi et al. 2017a).

A GPS Ionospheric Scintillation TEC monitor (GISTM, Van Dierendonck et al. 1993) receiver, 
consisting of a dual-frequency receiver with a low phase noise that is required for monitoring phase scintillation, is installed in MZS since 2006. The GISTM located in MZS has been proven to be strategic in studying the formation and dynamics of the ionospheric irregularities and their effects on GNSS systems (see, e.g., Alfonsi et al. 2011; Spogli et al. 2013; Prikryl et al. 2011, 2015). The GISTM is able to compute the TEC from GPS L1 $(1575.42 \mathrm{MHz})$ and L2 $(1227.60 \mathrm{MHz})$ carrier phase signals. In specific, to measure ionospheric irregularities in a more consistent and reliable way, instead of considering TEC time series, we preferred to use the rate of TEC $(\mathrm{ROT}=\Delta \mathrm{TEC} / \Delta t, \Delta t=1 \mathrm{~min})$ time series, which are better suited to highlight small-scale variations of TEC superimposed on a slower and large-scale trend. In addition, the use of ROT allows being safe from unknown biases affecting the TEC determination (see, e.g., Ciraolo et al. 2007; Cesaroni et al. 2015). We selected only time windows for which the elevation angle of the satellite was higher than $30^{\circ}$ and the ionospheric pierce point at $350 \mathrm{~km}$ was taken within $500 \mathrm{~km}$ from the MZS zenith at the same altitude. This procedure minimizes the effects (like multipath) of the environment surrounding the GISTM that may mimic the signatures of the ionospheric irregularities in the sampled signals.

We also used 1-min values of the solar wind dynamic pressure and $\mathrm{AE}$ index from the OMNIWeb database (http://cdaweb.gsfc.nasa.gov/).

\section{Experimental results}

\section{The pulsation event}

Figure 1 reports the dynamical spectrum and $S N R(f)$ of the total horizontal magnetic field (upper and middle panels) and the AE index and solar wind dynamic pressure (bottom panel) between 0200 and 1400 UT on 22 February 2007. A significant Pc1 pulsations activity is present between 0200 and 1300 UT, i.e., during the local afternoon and premidnight sector; it is characterized by an $S N R(f)$ greater than $3(\sim 0.5$ in the log scale), corresponding to a noise lower than $25 \%$ of the total signal (black contours in the dynamical spectrum and yellowred colors in the dynamical $S N R(f)$ ). Such activity is distributed in the $200-300 \mathrm{mHz}$ frequency band especially between 0200 and 0330 UT while, in the time interval 0330-1300 UT, it appears to be more as monochromatic wave packets in the same frequency band. In addition to the Pc1 activity, impulsive, broadband wave power (associated to irregular $\mathrm{PiB}$ pulsations) is observed in the dynamical spectrum right after 0630, 0700 and $0900 \mathrm{UT}$, in correspondence with small AE increases; it is characterized by an $S N R(f)$ much lower than 3 .
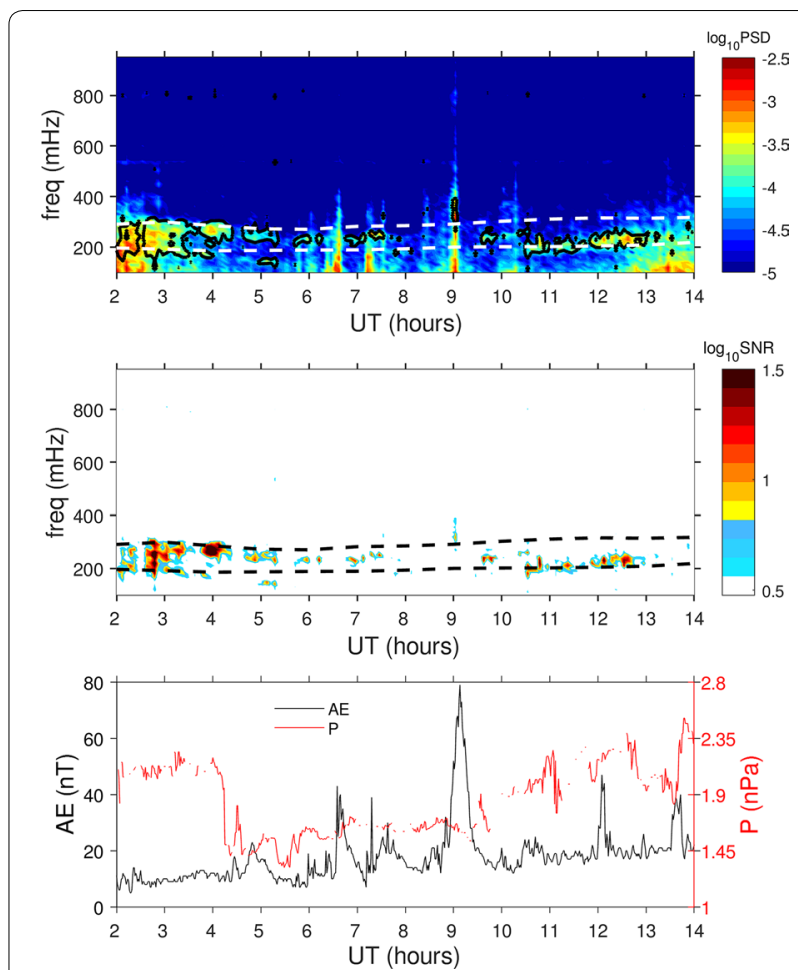

Fig. 1 The dynamical spectrum (top panel) and SNR(f) (middle panel) of the horizontal magnetic field at MZS on 22 February 2007 between 0200 and 1400 UT, compared with the simultaneous AE index (blue line) and solar wind pressure $P$ (red line) (bottom panel). Black contours in the dynamical spectrum indicate $\operatorname{SNR}(f)>3$

Pc1 activity roughly corresponds to an enhanced solar wind dynamic pressure, suggesting that the Pc1 pulsations could represent the ground signatures of EMIC waves generated just inside the magnetopause by magnetosphere compressions. Due to the horizontal propagation in the ionosphere, from the ground-based observations only it is not possible to identify the $L$ value corresponding to the wave injection region into the ionosphere (Lessard et al. 2019). Nevertheless, the observed pulsation frequency can provide some indication. For this purpose, we compared the observed pulsation frequency with the equatorial cyclotron frequency of $\mathrm{O}+, \mathrm{He}+$ and $\mathrm{H}+$ at the subsolar point for different $\mathrm{L}$ values, based on the T96 model (Tsyganenko and Stern 1996). Figure 1 shows that the pulsation activity appears at frequencies between the dashed curves superposed on the dynamical spectrum and $S N R(f)$, which correspond to the $\mathrm{He}+$ gyrofrequencies at $\mathrm{L}=9.5$ (lower curve) and $\mathrm{L}=7.5$ (upper curve); this suggests a possible injection region located between geomagnetic latitudes $68^{\circ} \mathrm{S}$ and $71^{\circ} \mathrm{S}$.

To characterize the observed pulsations, we computed the magnitude squared coherence $\gamma^{2}$ between $\mathrm{H}$ and $\mathrm{D}$ components and applied the polarization 


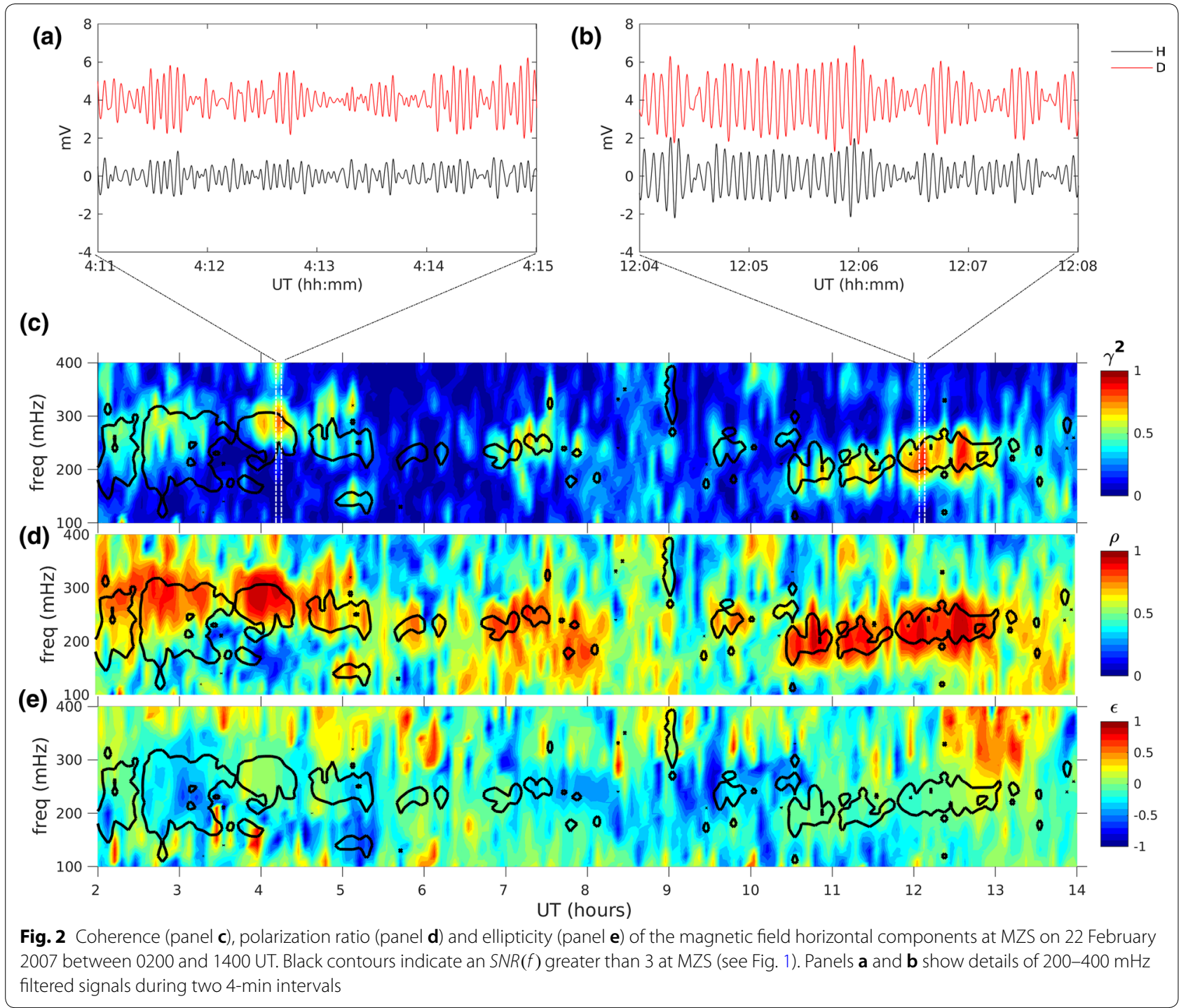

analysis by Fowler et al. (1967). Figure 2 shows that the coherence is high $\left(\gamma^{2}>0.6\right)$ in correspondence to Pc1 signals detected in Fig. 1, indicating fluctuations at the same frequencies in both components. The corresponding polarization ratio $\rho$ (i.e., the ratio between the polarized and total energy of the horizontal signal) is high $(\rho>0.7)$ and the ellipticity $\epsilon$ (i.e., the ratio between the minor and major axis of the polarization ellipse) is close to zero (i.e., $|\epsilon| \leq 0.2)$ indicating linearly polarized pulsations. This feature is expected for pulsations propagating in the ionospheric waveguide well past from the injection region (Greifinger 1972). Two examples of coherent, linearly polarized pulsations are presented in the two upper panels of Fig. 2 during two 4 -min intervals just after $\sim 04$ UT and $\sim 12 \mathrm{UT}$, respectively; both reveal clear waveforms in both horizontal components.

\section{The ionospheric irregularities}

To examine the possible effects on ionospheric conditions, we analyzed ROT data. Upper and lower panels on the left side of Fig. 3 respectively show the time series (smoothed over 15-min) of the geomagnetic field fluctuation power, integrated in the $200-300 \mathrm{mHz}$ frequency band characterized by significant, linear polarized Pc1 signals (see Figs. 1 and 2), and the ROT time series, as recorded from different satellites in the field of view of MZS. The right side of the figure shows corresponding ionospheric pierce points of satellites, assumed located at an altitude of $350 \mathrm{~km}$. A good correspondence can be noted between Pc1 power enhancements and intense ROT fluctuations (ROT $\geq 1 \mathrm{TECu}$ / $\mathrm{min}$ ); at the same UT, similar fluctuations are observed by satellites with close ionospheric pierce points. 


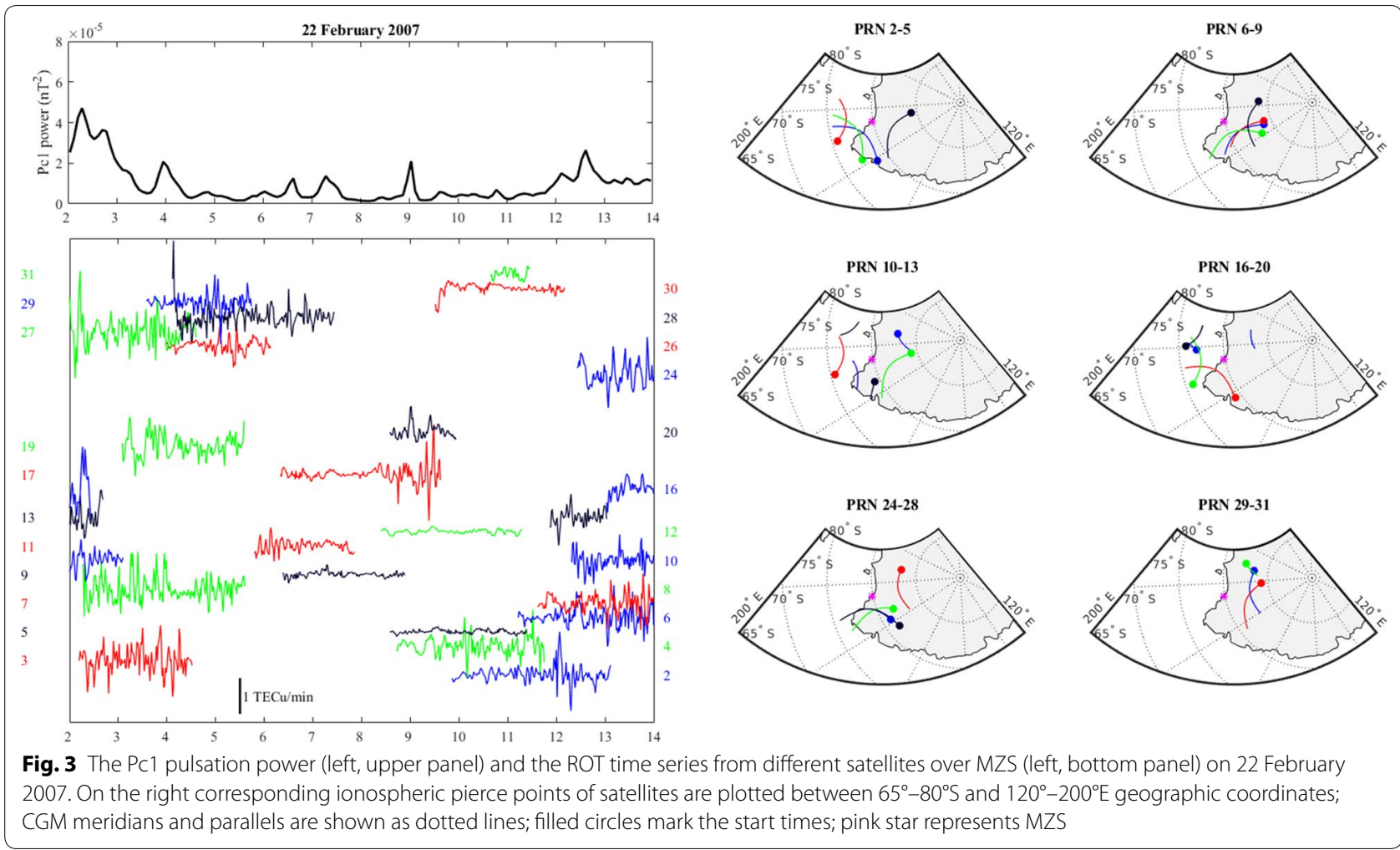

To better examine such correspondence, we computed, for each satellite, a moving variance over 5-min interval with a step size of $5 \mathrm{~min}$ (i.e., without overlap); then, for each interval, we averaged the variances corresponding to satellites observing intense ROT fluctuations, applying a smoothing over $15 \mathrm{~min}$. The average variance represents a measurement of the ionospheric activity and can be compared with the Pc1 pulsation power, as shown in Fig. 4 (upper panel) where the two quantities show a similar long-term trend and a general correspondence. We also computed the correlation coefficient between the ROT variance and the pulsation power and found a value of 0.74 ( 0.76 considering only the time intervals characterized by an $S N R(f)$ greater than 3, black thick line). To speculate about the nature of the ionospheric irregularities highlighted by ROT variations, we investigated also the phase $\left(\sigma_{\varphi}\right)$ and amplitude (S4) scintillation indices for every satellite-receiver link, defined as (Fremouw et al. 1978).

$$
\sigma_{\varphi}=\sqrt{\left\langle\varphi_{\text {detr }}^{2}\right\rangle-\left\langle\varphi_{\text {detr }}^{2}\right\rangle} \quad S 4=\sqrt{\frac{\left\langle S I^{2}\right\rangle-\langle S I\rangle^{2}}{\langle S I\rangle^{2}}}
$$

where $S I$ is the received signal intensity, $\varphi_{\text {detr }}$ is the detrended GPS L1 signal phase and $\langle\cdots\rangle$ indicates the time average over a defined window, set to $1 \mathrm{~min}$. A sampling rate of $50 \mathrm{~Hz}$ allows getting scintillation indices based on 3000 samples. Even though the recent literature has highlighted how the phase detrending is a delicate issue (see., e.g., McCaffrey and Jayachandran 2019 and reference therein), here we follow the standard recommendations by Van Dierendonck et al. (1993) and detrending is accomplished by means of a sixth-order Butterworth filter with a $0.1 \mathrm{~Hz}$ cutoff frequency. Applying this phase detrending scheme, enhancements of $\sigma_{\varphi}$ may include both refractive, mainly due to large-scale irregularities, and diffractive effects, due to small-scale irregularities, while enhancements of $S 4$ are always due only to diffractive effects on the GNSS signals (see., e.g., McCaffrey and Jayachandran 2019; De Franceschi et al. 2019). The separation between small- and large-scale irregularities is given by the Fresnel's filtering mechanism (Yeh and Liu 1982). Thus by comparing the time profile of both scintillation indices, the nature of the irregularities triggering the observed scintillation pattern can be drawn, in terms of involved spatial scales.

The time profile of 1-min scintillation indices $\sigma_{\varphi}$ and S4 during 22 February 2007 is reported in the middle and bottom panels of Fig. 4, respectively. Different colors represent different satellites in the field of view of MZS. Since no significant enhancements of $S 4$ are found corresponding to those of $\sigma_{\varphi}$ and according to the abovementioned phase detrending procedure, the time profiles indicate that phase fluctuations are purely refractive, i.e., 

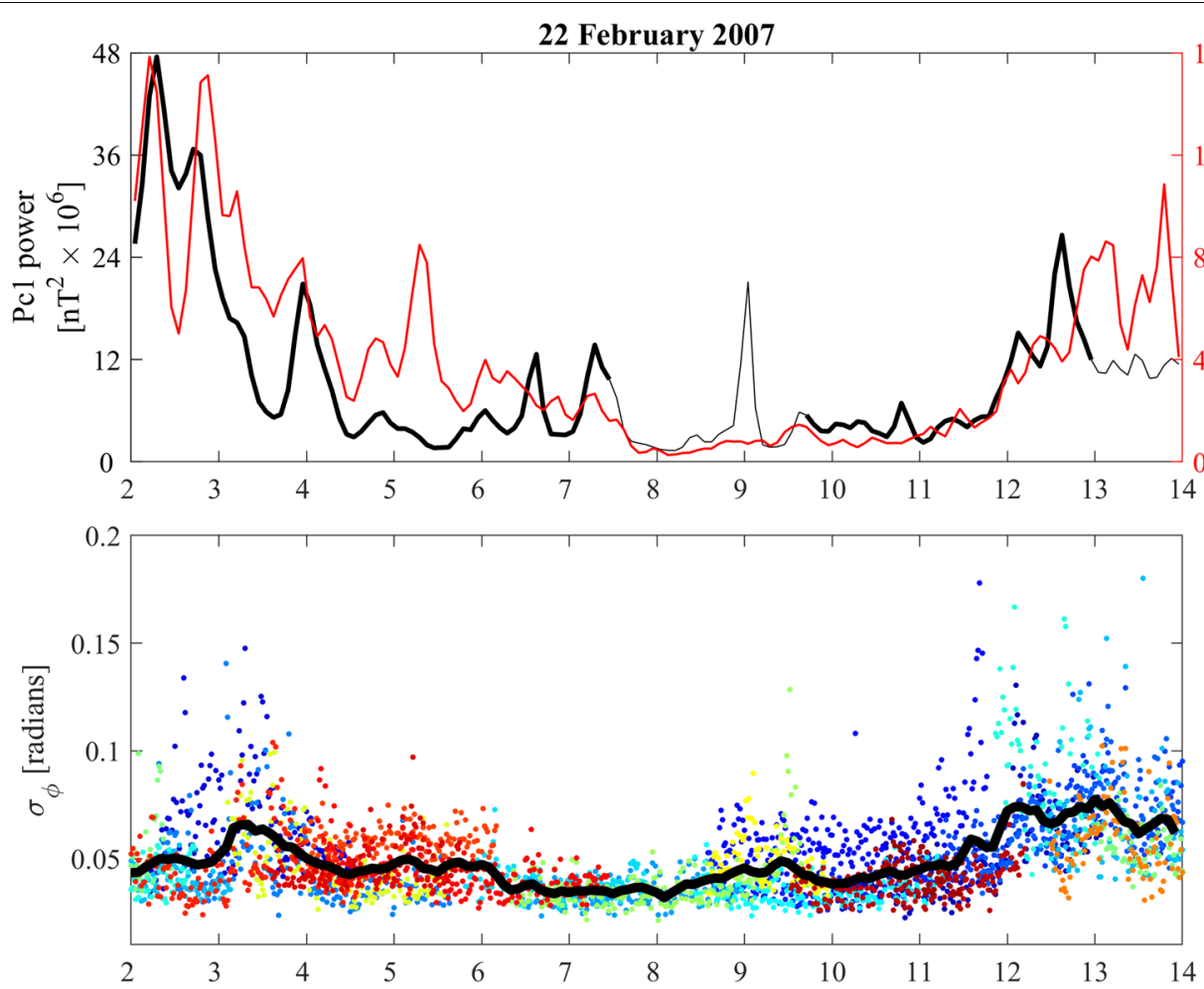

PRN
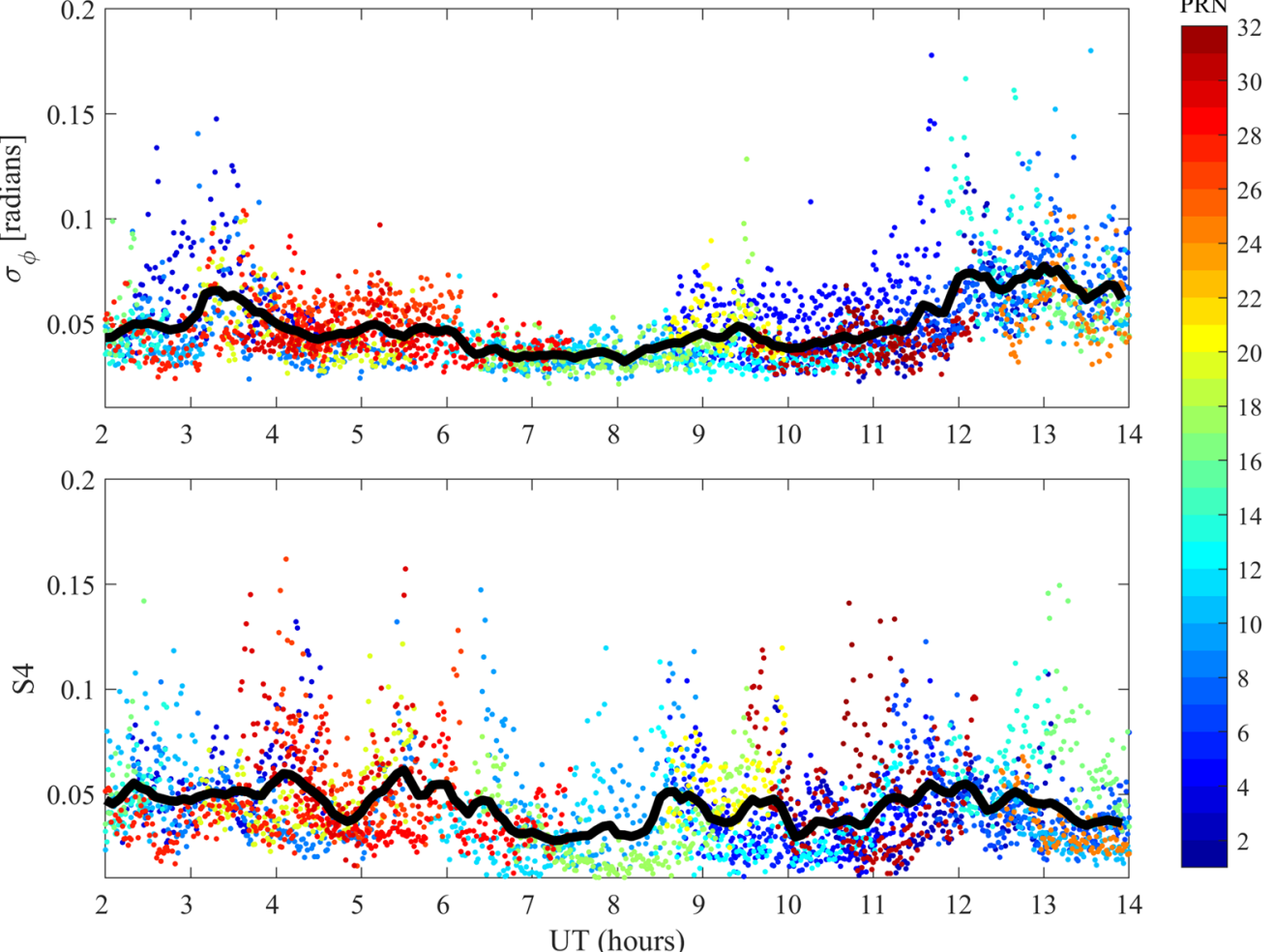

Fig. 4 Top panel: the PC1 pulsation power (thin black line) and the average variance of ROT (red line) on 22 February 2007. The thick black line highlights the pulsation power in correspondence to the time intervals characterized by an SNR greater than 3. Middle and bottom panels show respectively the 1-min phase $\sigma_{\varphi}$ and the amplitude $\$ 4$ scintillation indexes on 22 February 2007 (different colors represent different satellites in the field of view of MZS; the black line is the 5-min average)

mainly triggered by irregularities having a typical scale size larger than the Fresnel's length for GNSS signals, of the order of few hundreds of meters. The 5 -min averaged $\sigma_{\varphi}$ (smoothed over 15-min; solid line in the middle panel) well follows the Pc1 power and ROT variance (the correlation coefficients are 0.60 and 0.70 , respectively). At the same time, the 5-min averages of $S 4$ (solid line in the bottom panel) poorly correspond to the Pc1 power and the ROT variance (the correlation coefficients are 0.18 and 0.36 , respectively).
Therefore, since ROT is derived from TEC measurements and TEC is derived from a phase difference, the fluctuations found in $\sigma_{\varphi}$ are strictly linked to ROT ones. Moreover, the observed correspondence between the phase scintillation index and the Pc1 power represents the evidence that EMIC waves can lead to ionospheric irregularities causing phase scintillations. 


\section{Discussion}

We present a comparative study of ULF geomagnetic fluctuations and TEC variations measured at the highlatitude station MZS on 22 February 2007. For the first time to our knowledge, we report evidence of a correspondence between an enhanced Pc1 pulsation power and the presence of ionospheric irregularities.

In specific, we examined the occurrence of ROT fluctuations as an indicative of ionospheric irregularities. The results show that, when a significant Pc1 activity is observed at MZS, also the ROT time series exhibits intense fluctuations, indicating the presence of electron density gradients, well related to enhancements of the Pc1 power. A possible link between the Pc1 activity and the ionospheric irregularities is represented by the energetic electron precipitation which, driven by EMIC waves, might produce ionization through the atmospheric layers. An additional, interesting result is the close correspondence between the Pc1 activity and ROT fluctuations and the phase scintillation index; such correspondence suggests that EMIC waves can produce ionospheric irregularities, with typical scale sizes above few hundreds of meters, causing phase scintillations.

Although a geomagnetically quiet day was examined, we observed Pc1 fluctuations at MZS. Coherent, linearly polarized pulsations occurred at the Pc1 lower frequencies, i.e., between 200 and $300 \mathrm{mHz}$, approximately in correspondence to increases of the solar wind pressure. With regard to this, Engebretson et al. (2002) found that, at high latitudes, a major part of Pc1 events is associated with magnetosphere compressions and undisturbed magnetospheric conditions. The waves, generated by the magnetospheric compressions near the equatorial plane and just inside the magnetopause, are observed mostly at L-shell between 8 and 10 (corresponding respectively to geomagnetic latitudes of $\sim 69^{\circ}$ and $\sim 72^{\circ}$; Usanova et al. 2012). They can be detected even at the boundaries of the polar cap since they can propagate along the outermost closed field lines into the ionosphere and then in the ionospheric waveguide, more efficiently in the poleward direction (Kim et al. 2010, 2011; Regi et al. 2017a). Considering a wave power attenuation of $\sim 10 \mathrm{~dB} / 1000 \mathrm{~km}$ during the propagation in the waveguide (Kim et al. 2011), we believe that waves may be observed over a distance of the order of thousands of kilometers. Thus, the Pc1 waves observed in the present study at MZS could be injected into the ionosphere at a somewhat lower latitude (we tentatively estimated $71^{\circ}-68^{\circ} \mathrm{S}$ ). On this regard, the availability of simultaneous magnetic measurements (only the D component was available) at Concordia station (DMC, Dome C, Antarctica, geographic coordinates $75.11^{\circ} \mathrm{S}, 123.40^{\circ} \mathrm{E}$; corrected geomagnetic coordinates $88.83^{\circ} \mathrm{S}, 55.62^{\circ} \mathrm{E} ; \mathrm{LT}=\mathrm{UT}+8, \mathrm{MLT}=\mathrm{UT}-1$, at a distance of $\sim 1200 \mathrm{~km}$ from MZS) allows us to examine if such waves are observed also at a higher geomagnetic latitude station, located at approximately the same geographic latitude but at a different longitude. Figure 5 shows the dynamical spectrum and $S N R(f)$ of the D component at DMC and the coherence between the D components at MZS and DMC. Significant signals are detected also at DMC, corresponding in frequency and time to those of MZS; moreover, the high coherence $(\geq 0.8)$ indicates a clear relationship between magnetic field fluctuations at the two stations. This result indicates that the two stations, at a distance of a thousand of kilometers, observe waves that propagated, maybe along different paths, in the ionospheric waveguide from the same injection region at a lower geomagnetic latitude.

In this context, we found useful to analyze searchcoil data from the Finnish pulsation magnetometer array $(\mathrm{MLT} \sim \mathrm{UT}+2, \mathrm{LT} \sim \mathrm{UT}+2)$. Figure 6 shows the dynamical spectra of the total horizontal component at Barentsburg (BAR, L=15.8), Kilpisjarvi (KIL, $\mathrm{L}=6.2$ ), Ivalo (IVA, $\mathrm{L}=5.9$ ), Sodankyla (SOD, $\mathrm{L}=5.4$ ), Rovaniemi (ROV, L=5.1), Oulu (OUL, L=4.6) and Nurmijarvi (NUR, L=3.4). Besides higher frequency features, the figure shows that a narrowband signal in the range $200-300 \mathrm{mHz}$, as the one observed at MZS, clearly emerges from 0830 UT (i.e. 0630 LT) when stations enter the dayside sector. The pulsation power is high at $\mathrm{L} \sim 5-6$, attenuates at BAR, at polar latitudes, while almost disappears at the subauroral station NUR. The comparison between stations at $\mathrm{L}=5-6$ shows that the power integrated between 200 and $300 \mathrm{mHz}$ maximizes at KIL and decreases with decreasing $\mathrm{L}$ value, indicating that the power peak corresponds to a latitude greater than $66.2^{\circ} \mathrm{S}$. This result is consistent with our suggestion that waves propagate from the equatorial region just inside the magnetopause, where they are generated, along the outer closed magnetic field lines up to the auroral ionosphere, both southward and northward; from the injection region into the ionosphere they propagate in the waveguide and are observed also at polar latitudes. In particular, the comparison of the spectra at BAR and MZS (Fig. 7) shows a close correspondence between 0800 and $1300 \mathrm{UT}$, indicating that the waves can be observed in both hemispheres at stations located in open field line regions.

The observed correspondence between Pc1 power enhancements and the occurrence of ionosphere irregularities may be tentatively interpreted in terms of two different scenarios:

1. A causal relationship between the magnetospheric electron precipitation, due to Pc1 events, and ionospheric electron density variations and irregularities; 


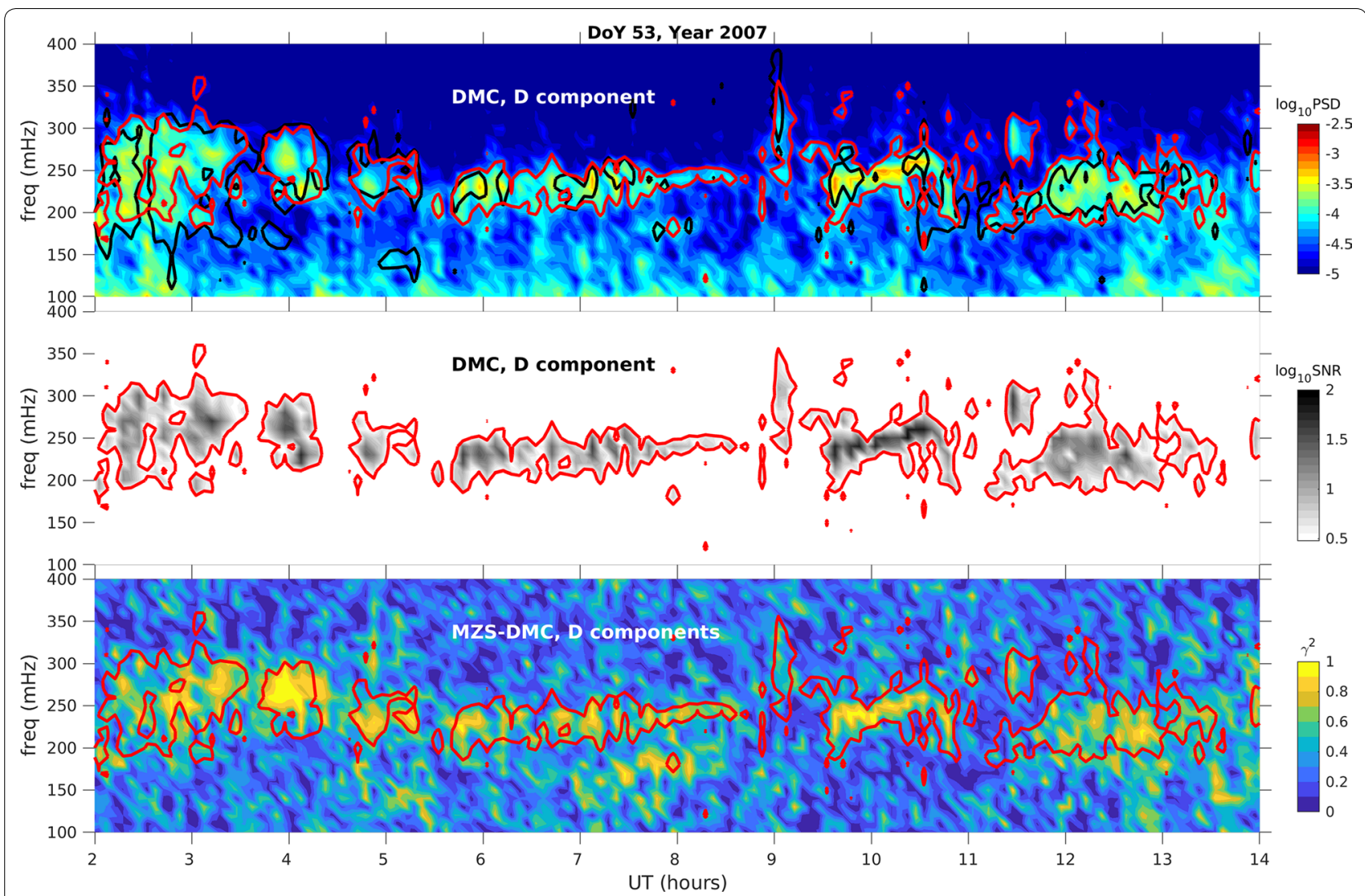

Fig. 5 The dynamical spectrum (top panel) and SNR(f) (middle panel) of PC1 pulsations at DMC on 22 February 2007 between 0200 and 1400 UT, and the coherence between D components at MZS and DMC (bottom panel). Black and red contours indicate an SNR $(f)$ greater than 3 at MZS and DMC, respectively

2. Direct effects of the variable electromagnetic fields of waves on ionospheric electrons.

Regarding the first mechanism, it is worth highlighting that TEC variations refer to the whole satellite-receiver path, including also low altitudes. The $\mathrm{MeV}$ electrons involved in EMIC wave activity deposit most of their energy below $60 \mathrm{~km}$ (Turunen et al. 2008). On the other hand, recent studies have shown experimental evidence that lower energy (200-300 keV) EMIC-driven electron precipitation not only is possible (Clilverd et al. 2015; Rodger et al. 2015) but also predominant (Hendry et al. 2017). Such precipitation would influence more effectively ionospheric altitudes of $100-120 \mathrm{~km}$ (Turunen et al. 2008). The hypothesis of a causal relationship presents a criticality in that the electron precipitation (with a latitudinal and longitudinal width of $2-3^{\circ}$ and $3 \mathrm{~h}$ magnetic local time, respectively, Clilverd et al. 2015) and the corresponding ionospheric effects should occur close to the Pc1 injection region, which is not above MZS. However, we remark that the region investigated by the ROT analysis is not restricted above the station, but it extends over a radius of about $500 \mathrm{~km}$ around it, where the effects of the electron precipitation could still be measured.

To check the second hypothesis, that is the interpretation of the correspondence of ionospheric irregularities with the Pc1 wave activity in terms of the direct effects of the variable electromagnetic fields of waves on ionospheric electrons, we made a spectral analysis of the highresolution time series of ROT (i.e., $\Delta \mathrm{TEC} / \Delta t, \Delta t=1 \mathrm{~s}$ ). The corresponding dynamical spectrum, shown in Fig. 8, reveals only weak and sporadic correspondences with the Pc1 dynamical spectrum and undefined evidence of oscillations at the same frequencies $(200-300 \mathrm{mHz})$ of the observed Pc1 waves (see Fig. 1, upper panel). It is worth noting that, in a recent study, Watson et al. (2016) found a clear link between TEC fluctuations and geomagnetic field fluctuations in a frequency range much lower $(6.7-22 \mathrm{mHz})$ than that analyzed in our study $(0.2-1 \mathrm{~Hz})$.

\section{Summary and conclusions}

We examined a Pc1 event observed at a high-latitude station during geomagnetic quiet conditions, with the aim at looking for possible correspondences with the 


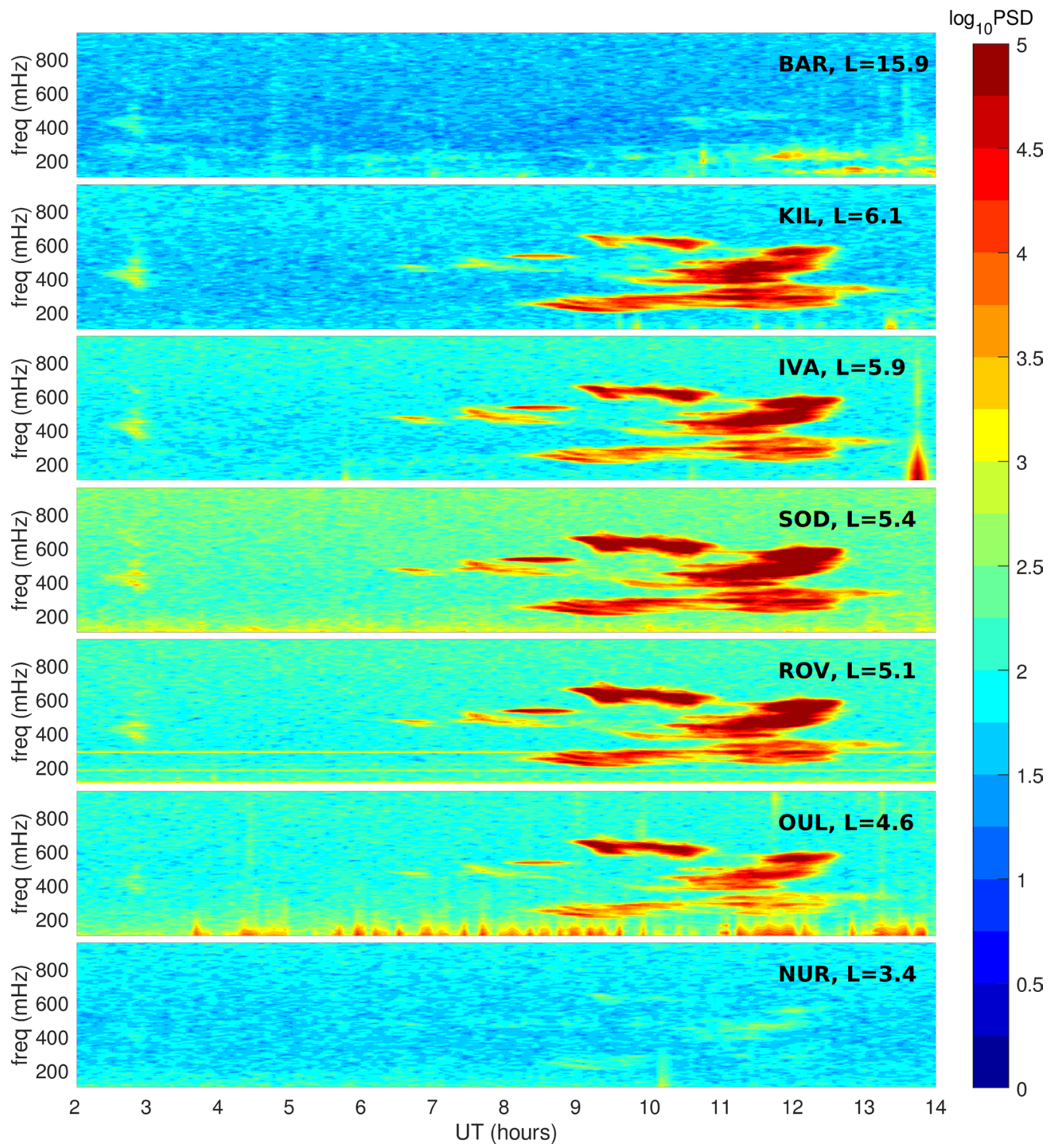

Fig. 6 The dynamical spectra of PC1 pulsations along the Finnish pulsation magnetometer chain on 22 February 2007 between 0200 and 1400 UT

ionospheric response. Our results can be summarized as follows:

1. The pulsation activity is enhanced in correspondence to solar wind dynamical pressure increases;

2. Pulsations of equal frequency are simultaneously observed at polar and auroral geomagnetic latitudes;

3. Correspondence is found between the Pc1 pulsation activity and the occurrence of ionospheric irregulari- ties, as clearly showed by the analysis of ROT fluctuations.

The study clearly shows that signatures of EMIC waves, driven by increased solar wind pressure, can be observed also at polar latitudes, simultaneously in both hemispheres, due to their propagation in the ionospheric waveguide. Such waves, generated just inside the magnetopause, propagate through the magnetosphere and transmit as Alfven waves along geomagnetic field lines 


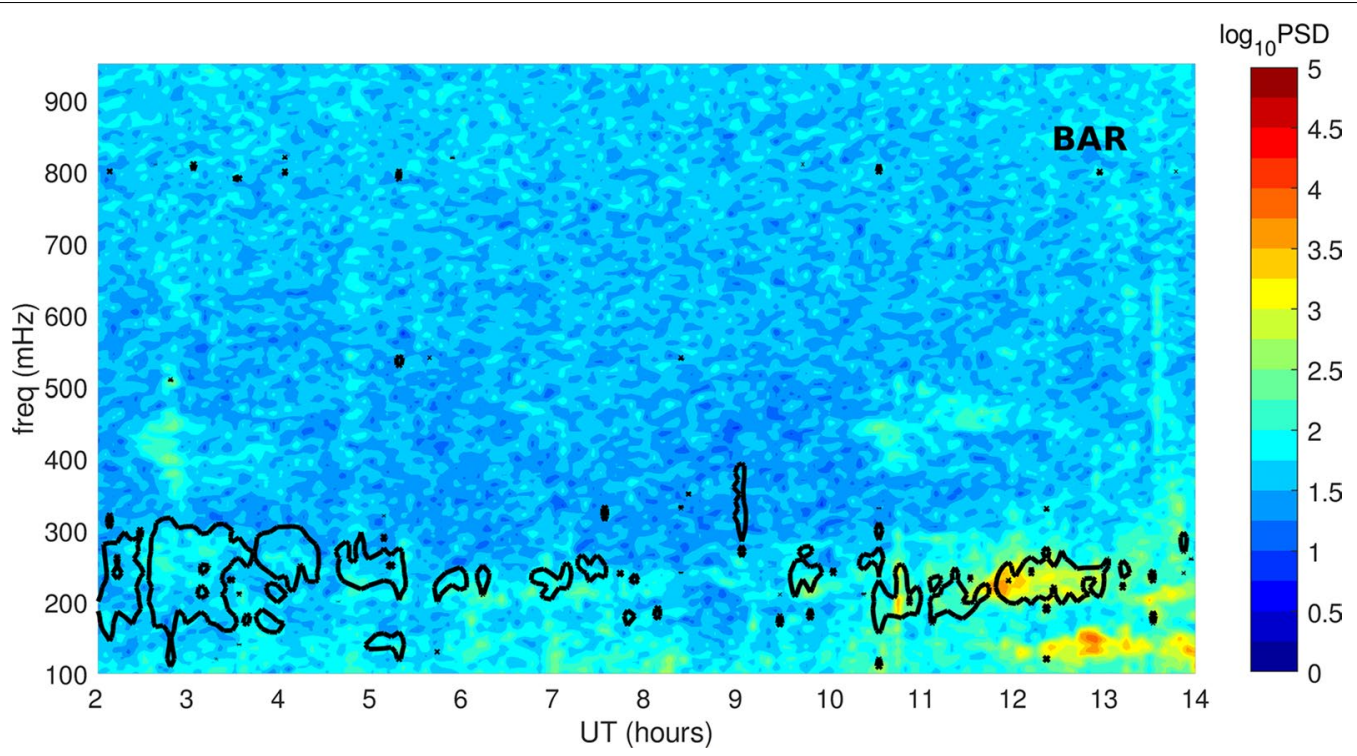

Fig. 7 The dynamical spectrum of PC1 pulsations at BAR $(L=15.8)$. The black contour indicates the SNR( $f)$ greater than 3 at MZS

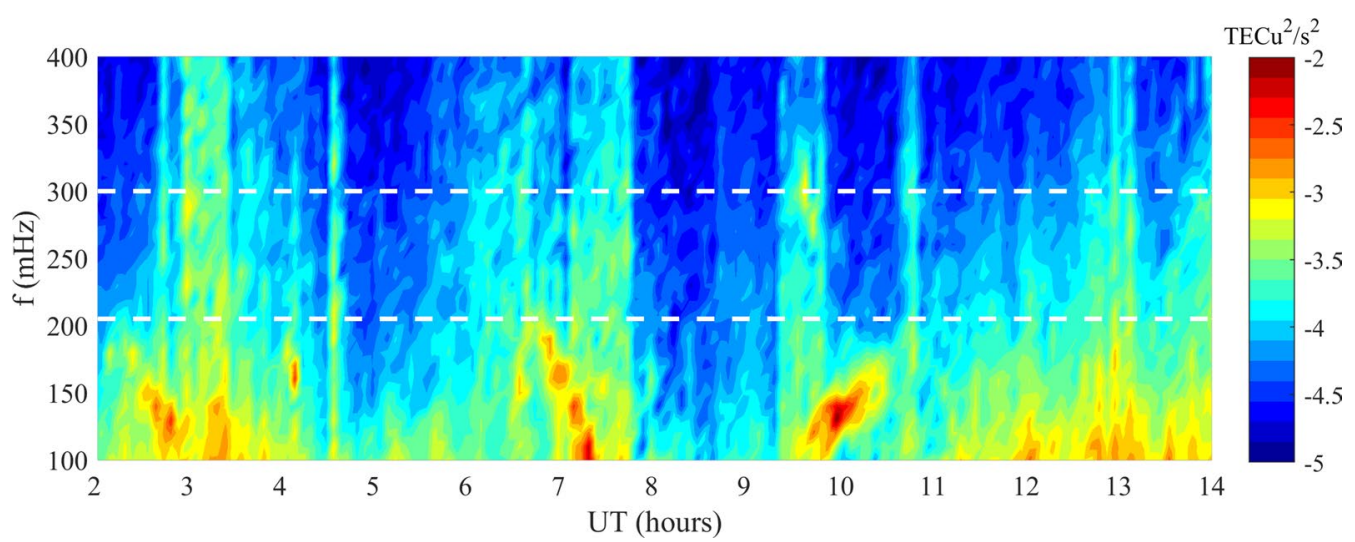

Fig. 8 The dynamical spectrum of 1-s resolution ROT time series between 0200 and 1400 UT on 22 February 2007. Dashed white lines indicate the frequency interval of interest

up to the auroral ionosphere. They can produce the precipitation of magnetospheric energetic electrons into the atmosphere, causing electron/ion density variations as measured by TEC fluctuations.

We believe that the observations of this work, although present a very interesting result, should be substantiated by further investigations, based on a number of events and additional data (satellite and/or riometer data) to be fully explained.

\begin{abstract}
Abbreviations
BAR: Barentsburg; DMC: Dome C; EMIC: Electromagnetic ion-cyclotron; IVA: Ivalo; KIL: Kilpisjarvi; LT: Local time; MLT: Magnetic local time; MZS: Mario Zucchelli station; NUR: Nurmijarvi; OUL: Oulu; PSD: Power spectral density; ROT: Rate of TEC; ROV: Rovaniemi; SOD: Sodankyla; S4: Amplitude scintillation index; $\sigma_{\varphi}:$ Phase scintillation index; TEC: Total electron content; ULF: Ultra-low frequency; UT: Universal time.
\end{abstract}

\section{Acknowledgements}

This research activity was supported by the Italian PNRA (Programma Nazionale di Ricerche in Antartide, PdR2013/B2.09). The authors also thank PNRA for GNSS data. The authors acknowledge J.H. King and N. Papatashvilli at NASA and CDAWeb for solar wind data (http://cdaweb.gsfc.nasa.gov). 


\section{Authors' contributions}

PF, MR and MDL made the ULF and TEC analysis, interpreted the results and were the major contributors in writing the manuscript; MP, CC and LS prepared the TEC time series. TR provided the Finnish pulsation magnetometer data. All participating authors contributed to the discussions. All authors read and approved the final manuscript.

\section{Funding}

The research activity of M. Regi was in part supported by the Consorzio "Area di Ricerca in Astrogeofisica".

\section{Availability of data and materials}

Measurements of the magnetic field fluctuations at Terra Nova Bay and Dome $\mathrm{C}$ can be requested to $\mathrm{M}$. De Lauretis at the following e-mail address: marcello. delauretis@aquila.infn.it. TEC data can be requested to M. Pezzopane and C. Cesaroni at the following e-mail addresses: michael.pezzopane@ingv.it and claudio.cesaroni@ingv.it. The Finnish pulsation magnetometer data are available by request from Sodankylä Geophysical Observatory at https://www.sgo. fi/Data/archive.php.

\section{Competing interests}

The authors declare that they have no competing interests.

\section{Author details}

${ }^{1}$ Dipartimento di Scienze Fisiche e Chimiche, Università degli Studi dell'Aquila, L'Aquila, Italy. ${ }^{2}$ Istituto Nazionale di Geofisica e Vulcanologia, Via di Vigna Murata 605, 00143 Rome, Italy. ${ }^{3}$ SpacEarth Technology, Rome, Italy. ${ }^{4}$ Sodankylä Geophysical Observatory, University of Oulu, FI-99600 Sodankylä, Finland.

Received: 28 November 2019 Accepted: 24 April 2020 Published online: 07 May 2020

\section{References}

Alfonsi L, Spogli L, De Franceschi G, Romano V, Aquino M, Dodson A, Mitchell CN (2011) Bipolar climatology of GPS ionospheric scintillation at solar minimum. Radio Sci. https://doi.org/10.1029/2010rs004571

Anderson BJ, Hamilton DG (1993) Electromagnetic ion cyclotron waves stimulated by modest magnetospheric compressions. J Geophys Res 98:11369-11382

Basu S, Groves KM, Quinn JM, Doherty P (1999) A comparison of TEC fluctuations and scintillations at Ascension Island. J Atmos Sol Terr Phys 61(16):1219-1226. https://doi.org/10.1016/S1364-6826(99)00052-8

Blum LW, Halford A, Millan R, Bonnell JW, Goldstein J, Usanova M, Engebretson M, Ohnsted M, Reeves G, Singer H, Clilverd M, Li X (2015) Observations of coincident EMIC wave activity and duskside energetic electron precipitation on 18-19 January 2013. Geophys Res Lett 42:5727-5735. https://doi. org/10.1002/2015GL065245

Cesaroni C, Spogli L, Alfonsi L, De Franceschi G, Ciraolo L, Monico JFG, Scotto C, Romano V, Aquino M, Bougard B (2015) L-band scintillations and calibrated total electron content gradients over Brazil during the last solar maximum. J Space Weat Space Clim 5:A36. https://doi.org/10.1051/ swsc/2015038

Ciraolo L, Azpilicueta F, Brunini C, Meza A, Radicella SM (2007) Calibration errors on experimental slant total electron content (TEC) determined with GPS. J Geod 81:111-120. https://doi.org/10.1007/s00190-006-0093-1

Clilverd MA, Rodger CJ, Moffat-Griffin T, Spanswick E, Breen P, Menk FW, Grew RS, Hayashi K, Mann IR (2010) Energetic outer radiation belt electron precipitation during recurrent solar activity. J Geophys Res 115:A08323. https://doi.org/10.1029/2009JA015204

Clilverd MA, Duthie R, Hardman R, Hendry AT, Rodger CJ, Raita T, Engebretson M, Lessard MR, Danskin D, Milling DK (2015) Electron precipitation from EMIC waves: a case study from 31 May 2013. J Geophys Res Space Phys 120:3618-3631. https://doi.org/10.1002/2015JA021090

De Franceschi G, Spogli L, Alfonsi L, Romano V, Cesaroni C, Hunstad I (2019) The ionospheric irregularities climatology over Svalbard from solar cycle 23. Sci Rep 9(1):1-14. https://doi.org/10.1038/s41598-019-44829-5
De Lauretis M, Francia P, Regi M, Villante U, Piancatelli A (2010) Pc3 pulsations in the polar cap and at low latitude. J Geophys Res 115:A11223. https:// doi.org/10.1029/2010JA015967

Elliot FD (1987) Handbook of Digital Signal Processing. Academic Press, Rockwell International Corporation, Anaheim, California, pp 999. https://doi. org/10.1016/C2009-0-21739-9

Engebretson MJ, Peterson WK, Posch JL, Klatt MR, Anderson BJ, Russell CT, Singer HJ, Arnoldy RL, Fukunishi H (2002) Observations of two types of Pc 1-2 pulsations in the outer dayside magnetosphere. J Geophys Res 107(A12):1451. https://doi.org/10.1029/2001JA000198

Engebretson MJ, Lessard MR, Bortnik J, Green JC, Horne RB, Detrick DL, Weatherwax AT, Manninen J, Petit NJ, Posch JL, Rose MC (2008) PC1-PC2 waves and energetic particle precipitation during and after magnetic storms: superposed epoch analysis and case studies. J Geophys Res 113:A01211. https://doi.org/10.1029/2007ja012362

Fedorov EN, Pilipenko VA, Engebretson MJ, Hartinger MD (2018) Transmission of a magnetospheric PC1 wave beam through the ionosphere to the ground. J Geophys Res Space Phys 123:3965-3982. https://doi. org/10.1029/2018JA025338

Fowler RA, Kotick BJ, Elliott RD (1967) Polarization analysis of natural and artificially induced geomagnetic micropulsations. J Geophys Res 72:28712883. https://doi.org/10.1029/JZ072i011p02871

Francia P, Regi M, De Lauretis M (2015) Signatures of the ULF geomagnetic activity in the surface air temperature in Antarctica. J Geophys Res 120(4):2452-2459. https://doi.org/10.1002/2015JA021011

Fraser BJ (1975) lonospheric duct propagation and PC 1 pulsation sources. J Geophys Res 80:2790-2796. https://doi.org/10.1029/JA080i019p02790

Fremouw EJ, Leadabrand RL, Livingston RC, Cousins MD, Rino CL, Fair BC, Long RA (1978) Early results from the DNA wideband satellite experimentcomplex-signal scintillation. Radio Sci 13(1):167-187

Fujita S, Tamao T (1988) Duct propagation of hydromagnetic waves in the upper ionosphere, 1, Electromagnetic field disturbances in high latitudes associated with localized incidence of a shear Alfvén wave. J Geophys Res 93(A12):14665-14673. https://doi.org/10.1029/JA093iA12p14665

Greifinger P (1972) Micropulsations from a finite source. J Geophys Res 77:2392-2396. https://doi.org/10.1029/JA077i013p02392

Greifinger C, Greifinger PS (1968) Theory of hydromagnetic propagation in the ionospheric waveguide. J Geophys Res 73(23):7473-7490. https://doi. org/10.1029/JA073i023p07473

Hayashi K, Kokubun S, Oguti T, Tsuruda K, Machida S, Kitamura T, Saka O, Watanabe T (1981) The extent of PC 1 source region in high latitudes. Can J Phys 59:1097-1105

Hendry AT, Rodger CJ, Clilverd MA (2017) Evidence of sub-MeV EMIC-driven electron precipitation. Geophys Res Lett 44:1210-1218. https://doi. org/10.1002/2016GL071807

Kim H, Lessard MR, Engebretson MJ, Lühr H (2010) Ducting characteristics of PC 1 waves at high latitudes on the ground and in space. J Geophys Res 115:A09310. https://doi.org/10.1029/2010JA015323

Kim H, Lessard M, Engebretson M, Young M (2011) Statistical study of Pc1-2 wave propagation characteristics in the high-latitude ionospheric waveguide. J Geophys Res 116:A07227. https://doi.org/10.1029/2010ja016355

Lessard MR, Paulson K, Spence HE, Weaver C, Engebretson MJ, Millan R, Woodger L, Halford A, Horne R, Rodger CJ, Hendry A (2019) Generation of EMIC waves and effects on particle precipitation during a solar wind pressure intensification with Bz>0 0. J Geophys Res Space Phys 124:4492-4508. https://doi.org/10.1029/2019JA026477

Manchester RN (1966) Propagation of Pc 1 micropulsations from high to low latitudes. J Geophys Res 71:3749-3754

McCaffrey AM, Jayachandran PT (2019) Determination of the refractive contribution to GPS phase "scintillation". J Geophys Res Space Phys 124(2):1454-1469

Menk FW (2011) Magnetospheric ULF waves: A review, in The Dynamic Magnetosphere. IAGA Spec. Sopron Book Ser., vol. 3, edited by W. Liu and M. Fujimoto, 223-256, Springer, Berlin

Mironova IA, Aplin KL, Arnold F, Bazilevskaya GA, Giles Harrison R, Krivolutsky AA, Nicoll KA, Rozanov EV, Turunen E, Usoskin IG (2015) Space Sci Rev 194:1. https://doi.org/10.1007/s11214-015-0185-4

Park JS, Kim KH, Shiokawa K, Lee DH, Lee E, Kwon HJ, Jin H, Jee G (2016) EMIC waves observed at geosynchronous orbit under quiet geomagnetic conditions (Kp $\leq 1)$. J Geophys Res Space Phys 121:1377-1390. https:// doi.org/10.1002/2015JA021968 
Ponomarenko PV, Fraser BJ, Menk FW, Ables ST, Morris RJ (2002) Cusp-latitude Pc3 spectra: band-limited and power-law components. Ann Geophys 20:1539-1551. https://doi.org/10.5194/angeo-20-1539-2002

Prikryl P, Spogli L, Jayachandran PT, Kinrade J, Mitchell CN, Ning B, Li G, Cilliers PJ, Terkildsen M, Danskin DW, Spanswick E, Donovan E, Watherwax AT, Bristow WA, Alfonsi L, De Franceschi G, Romano V, Ngwira CM, Opperman BDL (2011) Interhemispheric comparison of GPS phase scintillation at high latitudes during the magnetic-cloud-induced geomagnetic storm of 5-7 April 2010. Ann Geophys 29:2287-2304

Prikryl P, Ghoddousi-Fard R, Spogli L, Mitchell CN, Li G, Ning B, Cilliers PJ, Sreeja V, Aquino M, Terkildsen M, Jayachandran PT, Jiao Y, Morton YT, Ruohoniemi JM, Thomas EG, Zhang Y, Weatherwax AT, Alfonsi L, De Franceschi G, Romano V (2015) GPS phase scintillation at high latitudes during geomagnetic storms of 7-17 March 2012-Part 2: interhemispheric comparison. Annal Geophys 33:657-670. https://doi.org/10.5194/angeo $-33-657-2015$

Regi M, De Lauretis M, Redaelli G, Francia P (2016) ULF geomagnetic and polar cap potential signatures in the temperature and zonal wind reanalysis data in Antarctica. J Geophys Res 121(1):286-295. https://doi. org/10.1002/2015JA022104

Regi M, Marzocchetti M, Francia P, De Lauretis M (2017a) A statistical analysis of Pc1-2 waves at a near-cusp station in Antarctica. Earth Planets Space 69:152. https://doi.org/10.1186/s40623-017-0738-8

Regi M, Redaelli G, Francia P, De Lauretis M (2017b) ULF geomagnetic activity effects on tropospheric temperature, specific humidity, and cloud cover in Antarctica, during 2003-2010. J Geophys Res Atmos 122:6488-6501. https://doi.org/10.1002/2017JD027107

Rodger CJ, Raita T, Clilverd MA, Seppala A, Dietrich S, Thomson NR, Ulich T (2008) Observations of relativistic electron precipitation from the radiation belts driven by EMIC waves. Geophys Res Lett 35:L16106. https://doi. org/10.1029/2008GL034804

Rodger CJ, Hendry AT, Clilverd MA, Kletzing CA, Brundell JB, Reeves GD (2015) High-resolution in situ observations of electron precipitationcausing EMIC waves. Geophys Res Lett 42:9633-9641. https://doi. org/10.1002/2015GL066581

Spogli L, Alfonsi L, De Franceschi G, Romano V, Aquino MHO, Dodson A (2009) Climatology of GPS ionospheric scintillations over high and mid-latitude European regions. Ann Geophys 27(9):3429-3437

Spogli L, Alfonsi L, Cilliers PJ, Correia E, De Franceschi G, Mitchell CN, Romano V, Kinrade J, Cabrera MA (2013) GPS scintillations and total electron content climatology in the southern low, middle and high latitude regions. Ann Geophys-IT 56(2):R0220. https://doi.org/10.4401/ag-6240

Tsyganenko NA, Stern DP (1996) A new-generation global magnetosphere field model based on spacecraft magnetometer data. ISTP Newsletter 6(1):21

Turunen E, Verronen PT, Seppala A, Rodger CJ, Clilverd MA, Tamminen J, Enell CF, Ulich T (2008) Impact of different energies of precipitating particles on NOx generation in the middle and upper atmosphere during geomagnetic storms. J Atm Solar-Terr Phys 71:1176-1189. https://doi. org/10.1016/j.jastp.2008.07.005

Ukhorskiy AY, Shprits YY, Anderson BJ, Takahashi K, Thorne RM (2010) Rapid scattering of radiation belt electrons by storm-time EMIC waves. Geophys Res Lett 37:L09101. https://doi.org/10.1029/2010GL042906

Usanova ME, Mann IR, Rae IJ, Kale ZC, Angelopoulos V, Bonnell JW, Glassmeier $\mathrm{KH}$, Auster HU, Singer HJ (2008) Multipoint observations of magnetospheric compression-related EMIC PC1 waves by THEMIS and CARISMA. Geophys Res Lett 35:L17S25. https://doi.org/10.1029/2008GL034458

Usanova ME, Mann IR, Bortnik J, Shao L, Angelopoulos V (2012) THEMIS observations of electromagnetic ion cyclotron wave occurrence: dependence on $\mathrm{AE}$, SYMH, and solar wind dynamic pressure. J Geophys Res 117:A10218. https://doi.org/10.1029/2012JA018049

Van Dierendonck AJ, Klobuchar J, Hua Q (1993) lonospheric scintillation monitoring using commercial single frequency C/A code receivers, paper presented at the Sixth International Technical Meeting (ION GPS-93), Satell. Div., Inst. of Navig., Salt Lake City, Utah, 22-24 Sept

Watson C, Jayachandran PT, Singer HJ, Redmon RJ, Danskin D (2016) GPS TEC response to PC4 "giant pulsations". J Geophys Res Space Phys 121:17221735. https://doi.org/10.1002/2015JA022253

Welch PD (1967) The use of Fast Fourier Transform for the estimation of power spectra: a method based on time averaging over short, modified periodograms. IEEE Trans Audio Electr 15(2):70-73

Yeh KC, Liu CH (1982) Radio wave scintillations in the ionosphere. Proc IEEE 70(4):324-360

\section{Publisher's Note}

Springer Nature remains neutral with regard to jurisdictional claims in published maps and institutional affiliations.

\section{Submit your manuscript to a SpringerOpen ${ }^{\odot}$ journal and benefit from:}

- Convenient online submission

- Rigorous peer review

- Open access: articles freely available online

- High visibility within the field

- Retaining the copyright to your article

Submit your next manuscript at $\boldsymbol{\nabla}$ springeropen.com 